International Journal of Forensic Science \& Pathology (IJFP)

ISSN 2332-287X

\title{
Medicolegal Autopsies - Interesting and Incidental Findings
}

Research Article

Sulegaon $\mathrm{R}^{1}$, Kulkarni $\mathrm{D}^{2 *}$, Chulki $\mathrm{S}^{3}$

${ }^{1}$ Assistant Professor, Department of Pathology, Bidar Institute of Medical Sciences, Bidar, Karnataka, India.

${ }^{2}$ Associate Professor, Department of Pathology, Bidar Institute of Medical Sciences, Bidar, Karnataka, India.

${ }^{3}$ Professor and H.O.D., Department of Pathology, Bidar Institute of Medical Sciences, Bidar, Karnataka, India.

\begin{abstract}
An autopsy consists of a thorough examination of a corpse to determine the cause and manner of death and to evaluate any disease or injury.

This is a retrospective study of seven years where organs of total 53 medicolegal post - mortems were examined for histopathological lesions. The commonest cause of death was pulmonary edema. The most common incidental finding was Atherosclerosis which was associated with high risk factors of alcohol consumption and smoking.

Autopsy cause of death and contributing findings were based on the macro - and microscopic post-mortem findings combined with clinical information. Incidental histopathologic findings may not be found to influence the cause of death but nonetheless reveal many interesting facts related to epidemiology, which help in academic and research purpose. The significance of a careful postmortem examination can be summed up in the old saying "the dead teach the living".
\end{abstract}

Keywords: Histopathology; Medicolegal Postmortem; Incidental; Pulmonary Edema; Atherosclerosis.

\section{*Corresponding Author:}

\section{Dr. Dinesh Kulkarni,}

Associate Professor, Department of Pathology, Bidar Institute of Medical Sciences, Bidar, Karnataka State, India.

Tel: 09850018299

E-mail: drdineshkulkarni@gmail.com

Received: May 27, 2015

Accepted: July 28, 2015

Published: August 19, 2015

Citation: Sulegaon R, Kulkarni D, Chulki S (2015) Medicolegal Autopsies - Interesting and Incidental Findings. Int J Forensic Sci Pathol. 3(8), 156160. doi: http://dx.doi.org/10.19070/2332-287X-1500038

Copyright: Kulkarni D ${ }^{\odot} 2015$. This is an open-access article distributed under the terms of the Creative Commons Attribution License, which permits unrestricted use, distribution and reproduction in any medium, provided the original author and source are credited.

\section{Introduction}

The term "autopsy" is derived from the Ancient Greek autopsia, means "to see for oneself", autos ("oneself") and opsis ("eye") $[1,2]$. An autopsy also known as a post-mortem examination, is a highly specialized surgical procedure that consists of a thorough examination of a corpse to determine the cause and manner of death and to evaluate any disease or injury that may be present. Autopsies are performed for either legal or medical purposes. Giovanni Morgagni (1682-1771), celebrated as the father of anatomical pathology, wrote the first exhaustive work on pathology. By his work, Morgagni demolished the ancient humoral theory of disease and published his life time experience based on 700 postmortems and their corresponding clinical findings. He thus introduced the concept of clinicopathological correlation (CPC) establishing a coherent sequence of cause, lesions, symptoms and outcome of disease. Professor William Boyd in his unimitable style wrote "Pathology had its beginning on the autopsy table" [3].

There are two main types of autopsies [4]:

The Clinical or Academic Autopsy is performed with the consent of the relatives of the deceased to arrive at the diagnosis of cause of death where diagnosis could not be reached during the hospital stay, investigations and treatment or to confirm diagnosis where it was doubtful and are requested to determine the extent of a disease process or to evaluate therapy.

The Medico-legal or Forensic autopsy is performed on the instructions of the legal authority in circumstances relating to suspicious, sudden, obscure, unnatural, litigious or criminal deaths. Various histopathological findings unrelated to the cause of death are noticed in routine histopathological examination of medicolegal autopsies. These findings which sometimes are of practically no significance to the autopsy report however have an immense academic value. The final autopsy report contains the pathology of the organs which caused the death [1].

Hence autopsy remains the gold standard tool to ascertain the cause of death [5]. This study highlights the various incidental microscopic findings in medicolegal autopsies, which gain a prime importance in academic and research purposes. 


\section{Aims and Objectives}

This study was carried out with the following aims and objectives:

- To determine the histopathological findings related or unrelated to the cause of death.

- To highlight various incidental and interesting microscopic findings in autopsies.

\section{Materials and Methods}

Retrospective study of medicolegal autopsies for seven years from 2008-2014 was conducted in the Department of Pathology, Bidar Institute of Medical Sciences, Bidar, Karnataka.

The organs relevant to the case concerned were sent for histopathological examination. In most of the cases heart, liver, spleen, kidneys, brain and lungs were sent in formalin. Representative bits from the concerned organs were processed in a routine manner. The gross and microscopic findings were taken into consideration and a brief discussion of the salient features were made. All sec- tions were stained with haematoxylin and $\operatorname{eosin}(\mathrm{H} \& \mathrm{E})$ stain and special stains were used as and when required.

\section{Results}

The present study consists of 53 Medicolegal autopsies sent for histopathological examination from 2008 to 2014. Although the number of autopsies done was quite high, only 53 autopsies were sent for histopathological analysis. A detailed requisition form consisting of Patient identification, brief history, Autopsy findings, preliminary cause of death along with pieces of organs were received from Forensic Medicine Department. Data was collected and along with gross \& microscopic features was analysed and tabulated.

Among various histopathological findings, the commonest microscopic finding was pulmonary edema followed fatty liver, LVH and Atherosclerosis (Table 1) and the commonest incidental finding detected was Atherosclerosis (Table 2).

Out of 53 autopsies, 42 were male and 11 were female (Table 3)

Table 1. All Histopathological findings in Autopsies.

\begin{tabular}{|c|c|c|}
\hline S1. No & Finding & No. of Cases \\
\hline 1 & Pulmonary edema & 20 \\
\hline 2 & Fatty liver & 10 \\
\hline 3 & Left ventricular Hypertrophy $(\mathrm{LVH})$ & 8 \\
\hline 4 & Atherosclerosis & 7 \\
\hline 5 & CVC Lung & 6 \\
\hline 6 & Tuberculosis & 5 \\
\hline 7 & Bronchopneumonia & 4 \\
\hline 8 & Encephalitis & 3 \\
\hline 9 & Intrauterine POC & 3 \\
\hline 10 & CVC Liver & 2 \\
\hline 11 & Decomposed & 5 \\
\hline
\end{tabular}

Table 2. Incidental findings in Autopsies.

\begin{tabular}{|c|c|}
\hline S1. No. & Incidental finding \\
\hline 1 & Atherosclerosis \\
\hline 2 & Encephalitis \\
\hline 3 & Chronic Glomerulonephritis \\
\hline 4 & Acute Tubular Necrosis \\
\hline 5 & Sickle cell Thrombi in all organs \\
\hline 6 & Artificial Mitral valve \\
\hline 7 & Right Atrial Thrombus \\
\hline 9 & Pericarditis \\
\hline 10 & Nephrosclerosis \\
\hline
\end{tabular}

Table 3. Gender distribution of Autopsies Brought to the Department.

\begin{tabular}{|c|c|}
\hline Age group & No. of cases \\
\hline Male & 42 \\
\hline Female & 11 \\
\hline Total & 53 \\
\hline
\end{tabular}


Table 4. Age distribution of Autopsies Brought to the Department.

\begin{tabular}{|c|c|}
\hline Age group & No. of cases \\
\hline $0-20$ & 7 \\
\hline $21-40$ & 32 \\
\hline $41-60$ & 13 \\
\hline $61-80$ & 1 \\
\hline$>80$ & NIL \\
\hline Total & 53 \\
\hline
\end{tabular}

and the commonest age group affected was between 21 - 40 years (Table 4).

After the detailed analysis of gross and microscopy of the various organs received we have found out various incidental and interesting lesions in different systems.

In cardiovascular system we came across with lesions like Atherosclerosis (Figure. 1), healed Infarct, Left ventricular hypertrophy (Figure. 2), Mitral stenosis, Artificial Mitral valve (Figure. 3), Right ventricular hypertrophy and a case of Atrial Thrombus (Figure. $4)$.

In respiratory system the most common lesion encountered was pulmonary edema. Other lesions seen were Fibrocaseous Tuberculosis (Figure. 5), miliary TB, Pnuemonia (broncho and lobar), Pleuritis and Pleural effusion and CVC lung.

In hepatobiliary system we found Miliary 'Tuberculosis, fatty liver and CVC liver. A specimen of spleen revealed multiple nodules on surface (Figure. 6) and nonreactive caseating granulomas with plenty of acid fast bacilli (Figure. 7).

The urinary system revealed Miliary Tuberculosis, Chronic glomerulonephritis (Figure. 8), acute tubular necrosis (ATN) and Sickle cell thrombi (Figure. 9).

In female genital system, cases of intrauterine products of conception were seen. A case of testicular torsion was observed in male genital system.

We diagnosed two cases of viral encephalitis and a case of intracranial haemorrhage. No lesions were detected in gastrointestinal system.

Not a single neoplastic lesion was detected in any of these autopsy specimen.

\section{Conclusion}

Autopsy is the gold standard to ascertain cause of death, particularly in settings with limited access to diagnostic testing during life [6].

From our autopsy study, we would like to conclude that, though incidental findings in autopsies may not be the cause of death but gives many information related to epidemiology of a disease. In our study, we found atherosclerosis to be the commonest incidental finding which led to IHD, LVH and sudden death in the 2040 years age group in males. This was associated with history of alcohol consumption and smoking can lead to quarrels, both of which are high risk factors contributing to development of IHD.

A detailed and both, prospective as well as retrospectives, studies on prevalence of certain diseases in the community might help to find out actual prevalence figures as well as a useful data in controlling/monitoring certain disease processes.

Figure 1. Shows presence of multiple Atheromas in ascending Aorta.

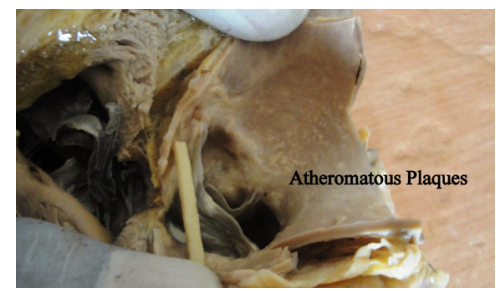

Figure 2. Shows cut surface of left ventricle showing hypertrophy.

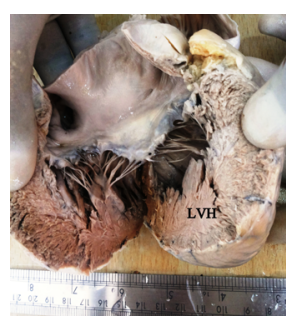


Figure 3. Shows Artificial (metal) mitral valve.

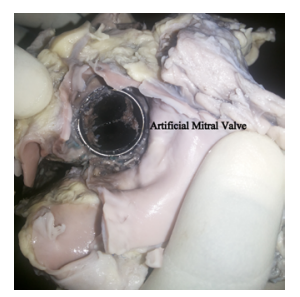

Figure 4. Shows a large Atrial thrombus.

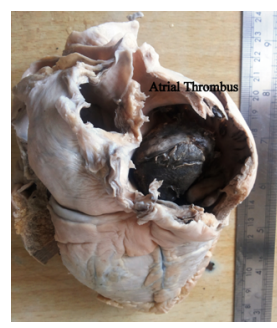

Figure 5. Shows thickened adherent pleura in fibrocaseous Tuberculosis.

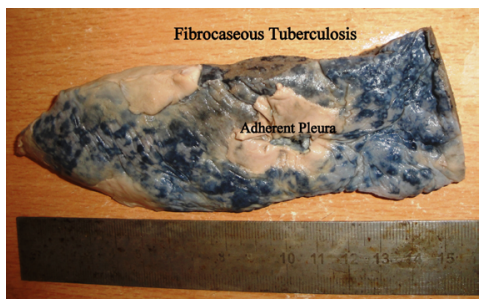

Figure 6. Shows multiple rounded whitish nodules from a patient of AIDS.

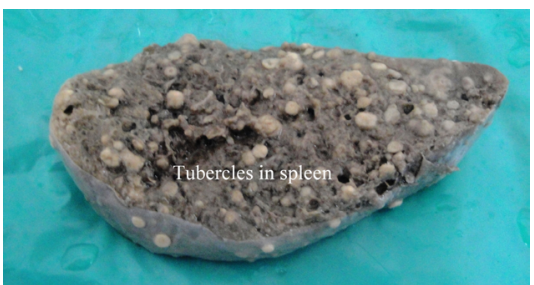

Figure 7. Section from nodules in spleen showing plenty of Acid fast bacilli (ZN; 10xX100x).

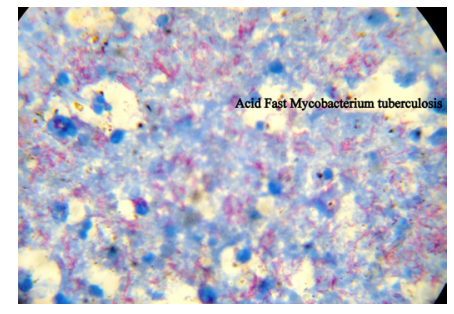

Figure 8. Shows small contracted granular kidney in chronic glomerulonephritis

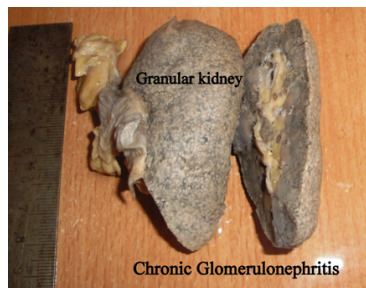


Figure 9. Section from kidney showing sickled RBC's in the vessels (H \& E; 10xX40X).

\section{References}

[1]. Ankur N Sarvaiya, Sahil I Panjavani, Shah NR, Shah CK (2014) Incidental and interesting histopathological findings in Medicolegal Autopsies. Int J Sci Res 3(1): 372-374.

[2]. Rothenberg, Kelly (2008) The Autopsy Through History. In Ayn Embarseddon, Forensic Science. Salem Press.

[3]. Harshmohan (2010) Introduction to pathology. In Textbook of Pathology. (6th edtn), Jaypee Brothers Medical Publishers (P) Ltd. 3.

[4]. Harshmohan (2010) Techniques for the study of pathology. In Textbook of
Pathology, (6th edtn), Jaypee Brothers Medical Publishers (P) Ltd. 9.

[5]. Indrajit Khandekar, Murkey PN, Tirpude BH (2009) Retrieval of organs, body parts and tissue from the medicolegal postmortems for mounting and research purpose: Some legal and ethical aspects. J Indian Acad Forensic Med 31(2): 171-174.

[6]. Cox JA, Lukande RL, Nelson AM, Mayanja-Kizza H, Colebunders R (2012) An Autopsy Study Describing Causes of Death and Comparing ClinicoPathological Findings among Hospitalized Patients in Kampala, Uganda. PLoS One 7(3): e33685. www.plosone.org 